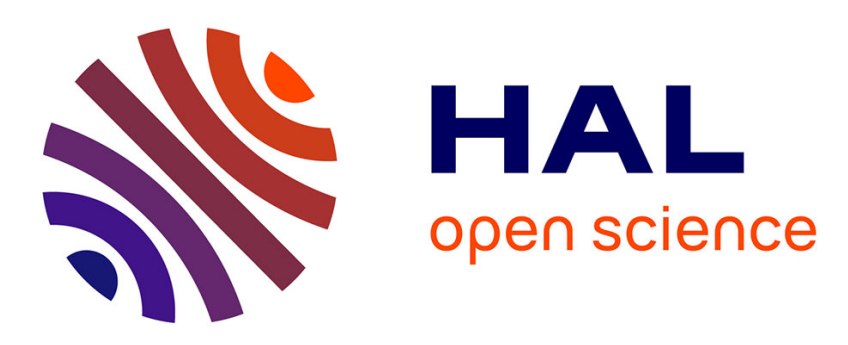

\title{
A finite difference model for undefined end boundary to analyse the heat transfer in dry sands
}

Somenath Mondal, Devendra N Singh, Anh Minh A.M. Tang, Jean-Michel

Pereira

\section{- To cite this version:}

Somenath Mondal, Devendra N Singh, Anh Minh A.M. Tang, Jean-Michel Pereira. A finite difference model for undefined end boundary to analyse the heat transfer in dry sands. International Journal of Geotechnical Engineering, 2022, 16 (2), pp.256-262. 10.1080/19386362.2020.1854972 . hal-03053673

\section{HAL Id: hal-03053673 \\ https://hal-enpc.archives-ouvertes.fr/hal-03053673}

Submitted on 11 Dec 2020

HAL is a multi-disciplinary open access archive for the deposit and dissemination of scientific research documents, whether they are published or not. The documents may come from teaching and research institutions in France or abroad, or from public or private research centers.
L'archive ouverte pluridisciplinaire HAL, est destinée au dépôt et à la diffusion de documents scientifiques de niveau recherche, publiés ou non, émanant des établissements d'enseignement et de recherche français ou étrangers, des laboratoires publics ou privés. 


\title{
A Finite Difference Model for Undefined End Boundary to Analyze the Heat Transfer in Dry Sands
}

\author{
Somenath Mondal ${ }^{*}$, Devendra N. Singh ${ }^{2}$, Anh M. Tang ${ }^{3 a}$ and Jean M. Pereira ${ }^{3 b}$ \\ ${ }^{1}$ Assistant Professor, Department of Civil Engineering, National Institute of Technology Jamshedpur, \\ Jharkhand-831014, India, smondal.ce@nitjsr.ac.in \\ ${ }^{2}$ Institute Chair Professor, Department of Civil Engineering, Indian Institute of Technology Bombay, Powai, \\ Mumbai-400076,India, dns@civil.iitb.ac.in \\ ${ }^{3 a}$ Research director, Université Paris-Est, Laboratoire Navier (UMR 8205), CNRS, ENPC, IFSTTAR, F- \\ 77455 Marne-la-Vallée, France, anhminh.tang@enpc.fr \\ ${ }^{36}$ Professor, Université Paris-Est, Laboratoire Navier (UMR 8205), CNRS, ENPC, IFSTTAR, F-77455 \\ Marne-la-Vallée, France, jean-michel.pereira@enpc.fr
}

\begin{abstract}
Accurate prediction of thermal regime (i.e., the variation of soil temperature, $\theta$, and heat flux, $\phi)$ to investigate the migration of thermal energy in soil mass, poses challenge to the geoenvironmental engineers while dealing with various thermo-active structures. In this context, several numerical approaches have been attempted to solve the heat transfer equation (HTE) for conduction to predict the thermal regime. However, most of them need accurate boundary condition defined and involve complicated numerical approach which is inconvenient for the practising engineers. Hence, an attempt has been made in the present study to develop a simplified, but numerically efficient, approach based on the finite difference method (FDM) to analyse one dimensional heat transfer in dry sands when the end boundary is not defined. Furthermore, a time dependent initial boundary condition has been applied to this model to simulate similar experimental condition and results have been compared vis-à-vis those obtained from the experiment and COMSOL Multiphysics ${ }^{\circledR}$ to validate the proposed approach.
\end{abstract}

Keywords: sands; thermal regime; heat transfer equation; numerical analysis; finite difference model;

\section{Introduction}

Contemporary geoenvironmental engineering and practices deal with design and construction of several thermo-active structures such as furnaces, boiler units, forging units, brick kilns and rocket launching pads, buried conduits and electrical cables, air conditioning ducts (Kadali et al. 2013), disposal facilities of waste from the nuclear and thermal power plants (Rao and Singh 1999; Krishnaiah and Singh 2004; Delage et al. 2010; Dao et al. 2015), underground crude oil storage tanks (Mandal et al. 2013; Padmakumar 2013; Usmani et al. 2015), oil carrying pipelines ( Brandon and Mitchell 1989; Abuel-Naga et al. 2008; Lee et al. 2010; Manthena and Singh 2001), solar ponds (Velmurugan and Srithar 2008), energy geostructures ( Knellwolf et al. 2011; Loveridge and Powrie 2013; Salciarini et al. 2013; Yavari et al. 2014; Di Donna et al. 2016; Faizal et al. 2016; McCartney et al. 2016), which result in conveyance of thermal energy through the soil mass. Moreover, activities like dissociation of gas hydrates by heating (Feng et al. 2015; Song et al. 2015, 2016) and exploitation of oil sand by steam assisted gravity drainage (SAGD) (Elsayed $e t$ al. 2015; Lazzaroni et al. 2016) and also soil-atmosphere interaction ( Heusinkveld et al. 2004; Ochsner et al. 2007; Cui et al. 2013) involve heat migration through soil mass. These applications necessitate studies to understand how heat migrates in the soil mass by means of predicting the thermal regime (i.e., time dependent temperature and thermal flux) in it.

In this context, several studies have been carried out to predict thermal regime of soil mass by solving HTE (Heat Transfer Equation) either numerically or analytically. Some of the broadly used

* Corresponding author. Tel.: +91-9064006324 
approaches are Finite Element Method (FEM) ( Timlin et al. 2002; Han and Huang 2002; Bittelli et al. 2008,), Finite Volume Method (LeVeque 2002), Finite Difference Method (FDM) (Sharratt et al. 1992; Han and Huang 2002; Wu and Sun 2004; Wang et al. 2011), Force Restore Method (FRM) ( Liebethal and Foken 2007; Gao et al. 2008). Moreover, different analytical methods like Harmonic Method, Laplace Transform Method, and Fourier Transform Method, have been considered by several researchers (Heusinkveld et al. 2004; Gao et al. 2007; Evett et al. 2012; Wang et al. 2012) to solve HTE in order to predict the thermal regime in soil mass (Mondal et al. 2017). Nonetheless, the major hindrance of some of the abovementioned methods is that they involve complicated mathematics which is not convenient to the practising engineers. Moreover, for any numerical approach, proper boundary conditions are necessary to be defined. On the contrary, many a times while performing experimental investigations, proper boundary conditions are not monitored. This results in a real challenge to adopt a numerical study in order to conduct comparative analysis between experimental and numerical outcomes of any particular problem.

Keeping this in view, an effort has been made to develop a computationally efficient and simplified numerical model based on FDM to predict (i) the end boundary and to estimate (ii) the realistic thermal regime in sandy soils, which would be very convenient for the practising geotechnical engineers. Furthermore, the results obtained from FDM and COMSOL Multiphysics $^{\circledR}$, a commercially available FEM based analysis tool, have been compared vis-à-vis with experimental results, details of which are presented in this paper.

The distinctiveness of this model lies in the fact that it is simpler than the complicated analytical solutions yet numerically efficient. This would make the model widely accepted among practicing engineers who are working in the projects of construction of thermo-active structures. Moreover, this FDM can be employed to define the appropriate boundary conditions (in case of comparative analysis between experimental investigations with undefined boundary) to obtain an accurate numerical solution.

\section{Statement of the Problem}

This section deals with the details of the problem investigated in the present study, which essentially has been derived from the experiments conducted by Mondal et al. (2016). A $20 \mathrm{~cm}$ long (L) column of the Indian standard sands, designated as SI (refer Table 1 for the thermal properties of the sands) was used in the experiments. A temperature of $60^{\circ} \mathrm{C}$ was applied at the top surface of this column, as depicted in Fig1a. Furthermore, as depicted in Fig1b, the flux sensors, and thermocouples were embedded at $5 \mathrm{~cm}$ and $9 \mathrm{~cm}$ depths, respectively, in the sample (Mondal et al. 2017). The heat gun was kept at a height of $400 \mathrm{~mm}$ which ensured uniform heat application at the top surface of the column. Since the lateral boundary is maintained adiabatic as explained in Mondal et al. (2016) and the base of the column is made up of aluminium, which has very high thermal conductivity as compared to that of sand, the bottom boundary of this column can be considered as the 'open end boundary' through which thermal flux could exit. As such, the heat transfer through this column can be assumed to be one-dimensional, and after a specific time, the steady-state condition could be achieved in it. Hence, the novelty of the present study is that it's an attempt to establish a simple numerical approach, based on finite difference method (FDM), to identify the correct end boundary conditions, which would facilitate determination of thermal regime for one-dimensional heat conduction in dry sands.

Table 1. Thermal Properties of Sand used in this study

\begin{tabular}{|c|c|c|c|}
\hline Sand & $\begin{array}{c}\text { Dry density }\left(\mathrm{y}_{\mathrm{d}}\right) \\
\left(\mathrm{g} / \mathrm{cm}^{3}\right)\end{array}$ & $\begin{array}{c}\text { Thermal Conductivity } \\
(k)\left(\mathrm{W} /{ }^{\circ} \mathrm{C} / \mathrm{m}\right)\end{array}$ & $\begin{array}{c}\text { Specific Heat }\left(C_{p}\right) \\
\left(\mathrm{J} / \mathrm{kg} /{ }^{\circ} \mathrm{C}\right)\end{array}$ \\
\hline SI & 1.556 & 0.315 & 171 \\
\hline
\end{tabular}

\section{The Proposed Methodology}


The one-dimensional heat conduction equation can be written as:

$$
\frac{\partial \theta}{\partial t}=\alpha \frac{\partial^{2} \theta}{\partial z^{2}}
$$

where $\theta(z, t)$ is the temperature in the soil mass, at the depth of $z$ and corresponding to time, $t$, and $\alpha$ is the thermal diffusivity of the soil mass which can be determined if $\kappa$, thermal conductivity and $C$, Specific heat for a particular bulk density, $\rho$, of the soil mass is known (refer Eq. 2).

$$
\alpha=\frac{\kappa}{\rho C}
$$

It should be noted that the conduction is the predominant mechanism of heat transfer through solids (Jackson and Taylor 1986; Mondal et al. 2018) and hence, equation of heat conduction is considered.

\subsection{The model based on the FDM}

The one-dimensional HTE, Eq. 1, is discretised in time and space using simple difference equations and ignoring the truncation error, which is negligibly small. Subsequently, the explicit solution has been obtained as:

$$
\theta_{i+1}^{n}=\frac{\alpha \Delta t}{(\Delta z)^{2}}\left(\theta_{i}^{n+1}-2 \theta_{i}^{n}+\theta_{i}^{n-1}\right)+\theta_{i}^{n}
$$

It is worth mentioning that the condition of stability for this explicit solution is $\frac{\alpha \Delta t}{(\Delta z)^{2}} \leq \frac{1}{2}$. As such, in order to maintain the stability, a time step of 30 seconds which corresponds to characteristic length of $1 \mathrm{~cm}$, has been chosen.

\subsection{Determination of the End boundary}

The purpose of this simple numerical method is to analyse the experimental data where the end boundary condition is not defined. As described by Mondal et al. (2016) neither the temperature nor the thermal flux was measured at the end boundary while performing the experiment. Hence, it became mandatory to device a methodology that could be utilized to define the end boundary. With this in view, beyond the considered depth of the model, L $(=20 \mathrm{~cm})$, an additional depth of the soil mass of length, $\Delta \mathrm{L}$, has been chosen (refer Fig. 2). This additional depth of the soil mass is beyond the zone of influence of the temperature applied at the top boundary, for a particular time, and is constrained by the bottom boundary. Hence, changes in the applied temperature at the top surface of the model would not be felt by the end boundary which is considered as the end point of the additional depth. As a result, at this end boundary the prevailing temperature could be considered as ambient when numerical simulation is being conducted. The obtained result, for different values of $\Delta \mathrm{L}$ were compared with the analytical solution of HTE (refer Eq. 4) for establishing the most suitable depth of end boundary.

$$
\theta(z, t)=\left(\theta_{\mathrm{j}}-\theta_{0}\right) \operatorname{erf}\left(\frac{z}{2 \sqrt{\alpha t}}\right)+\theta_{0}
$$

where $\theta_{\mathrm{j}}$ and $\theta_{0}$ are initial and applied temperature respectively.

\subsection{Time dependent boundary condition}

As described by Mondal et al. (2016), the top surface of the sand column takes some time to achieve the applied temperature (i.e., the temperature at which the heat gun is set). While, in case of the FDM, corresponding to the second time step, the first node is considered to have achieved the maximum applied temperature, which results in higher rate of heat transfer. Hence, to simulate the true experimental conditions, a step thermal loading of $0.4{ }^{0} \mathrm{C} / \mathrm{min}$ has been imposed at the second time step of the FDM, until the first node achieves the maximum applied temperature.

\section{Results}


To define the bottom end boundary for the FDM, a methodology has been adopted as described in Section 3.2 and the results are compared vis-a-vis the analytical solution (refer Eq. 4), as depicted in Fig 3. It can be observed from Figs. 3 (a) and (b) that the results obtained from the FDM, for an additional depth $(\Delta \mathrm{L})$ of $20 \mathrm{~cm}$, exhibit the best agreement with the results obtained from analytical solution. Based on this finding, the end boundary condition for the FDM was considered as an optimum additional depth of $20 \mathrm{~cm}$ when there is no significant improvement for further increment of $\Delta \mathrm{L}$. Moreover, the experimental data has been compared vis-à-vis the results obtained from the FDM and COMSOL Multiphysics ${ }^{\circledR}$. It is worth mentioning here that the lateral boundaries of the COMSOL model have been assumed to be 'adiabatic' and the bottom boundary has been assigned the ambient temperature like the FDM. Subsequently, a comparison between the results obtained from the experiments, and FDM and COMSOL Multiphysics ${ }^{\circledR}$ has been depicted in Fig 4 and Fig 5, respectively.

It can be noticed from Fig 4 that there is a good match between the experimental and FDM results. However, it can be noticed from Fig 5 that the COMSOL Multiphysics ${ }^{\circledR}$ predicts lower temperatures as compared to experimentally obtained results. Furthermore, it can be observed from Fig 6 that the temperature profile obtained from the FDM matches very well with the experimentally obtained temperature profile. However, Fig 7 exhibits not so good match between the temperature profiles obtained from COMSOL Multiphysics ${ }^{\circledR}$ simulation and the experiments.

\section{Concluding Remarks}

Prediction of realistic thermal regime in soil mass by means of mathematical approach enforces challenges to geoenvironmental practitioners. In this context, a simple FDM has been developed to solve one-dimensional HTE equation in order to establish thermal regime in sandy soil mass. A simple mathematical approach has been proposed to define end boundary for the FDM, as in case of the experiment the temperature at the end boundary could not be monitored. It is worth mentioning that the proposed numerical approach can be used for any dry sandy soil to define the end boundary and to determine the thermal regime. Moreover, experimentally obtained thermal regime has been compared vis-à-vis that obtained from the FDM and COMSOL Multiphysics ${ }^{\circledR}$ and it has been demonstrated that the FDM results match satisfactorily with experimental results as compared to the COMSOL Multiphysics ${ }^{\circledR}$. Hence, it is believed that the proposed FDM would be an efficient tool to estimate thermal regime in sandy soils. However, the applicability of the proposed model should be checked in clays to enhance its versatility.

\section{Acknowledgements}

The authors wish to acknowledge the support of the European Commission via the Marie Curie IRSES project GREAT 'Geotechnical and geological Responses to climate change: Exchanging Approaches and Technologies on a world-wide scale' (FP7-PEOPLE-2013-IRSES-612665) and the funding received from the Department of Electronics and Information Technology (DeitY), MCIT, Government of India, through the Center of Excellence in Nanoelectronics, Department of Electrical Engineering, IIT Bombay.

\section{References}

Abuel-Naga, H. M., Bergado, D. T., and Bouazza, A. (2008). "Thermal conductivity evolution of saturated clay under consolidation process." International Journal of Geomechanics, American Society of Civil Engineers, 8(2), 114-122. https://doi.org/10.1061/(ASCE)1532-3641(2008)8:2(114).

Bittelli, M., Ventura, F., Campbell, G. S., Snyder, R. L., Gallegati, F., and Pisa, P. R. (2008). "Coupling of heat, water vapor, and liquid water fluxes to compute evaporation in bare soils." Journal of Hydrology, 362(3-4), 191-205. https://doi.org/10.1016/j.jhydrol.2008.08.014. 
Brandon, T. L., and Mitchell, J. K. (1989). "Factors Influencing Thermal Resistivity of Sands." Journal of Geotechnical Engineering, American Society of Civil Engineers, 115(12), 1683 1698. https://doi.org/10.1061/(ASCE)0733-9410(1989)115:12(1683).

Cui, Y. J., Ta, A. N., Hemmati, S., Tang, A. M., and Gatmiri, B. (2013). "Experimental and numerical investigation of soil-atmosphere interaction." Engineering Geology, 165, 20-28. https://doi.org/10.1016/j.enggeo.2012.03.018.

Dao, L. Q., Cui, Y. J., Tang, A. M., Pereira, J. M., Li, X. L., and Sillen, X. (2015). "Impact of excavation damage on the thermo-hydro-mechanical properties of natural Boom Clay." Engineering Geology, 195, 196-205. https://doi.org/10.1016/j.enggeo.2015.06.011.

Delage, P., Cui, Y. J., and Tang, A. M. (2010). "Clays in radioactive waste disposal.” Journal of Rock Mechanics and Geotechnical Engineering, 2(2), 111-123. https://doi.org/10.3724/SP.J.1235.2010.00111.

Di Donna, A., Ferrari, A., and Laloui, L. (2016). "Experimental investigations of the soil-concrete interface: physical mechanisms, cyclic mobilization, and behaviour at different temperatures." Canadian Geotechnical Journal, NRC Research Press, 53(4), 659-672. https://doi.org/10.1139/cgj-2015-0294.

Elsayed, N. A., Barrufet, M. A., and El-Halwagi, M. M. (2015). “An integrated approach for incorporating thermal membrane distillation in treating water in heavy oil recovery using SAGD." Journal of Unconventional Oil and Gas Resources, 12, 6-14. https://doi.org/10.1016/j.juogr.2015.07.002.

Evett, S. R., Agam, N., Kustas, W. P., Colaizzi, P. D., and Schwartz, R. C. (2012). "Soil profile method for soil thermal diffusivity, conductivity and heat flux: Comparison to soil heat flux plates." Advances in Water Resources, 50, 41-54. https://doi.org/10.1016/j.advwatres.2012.04.012.

Faizal, M., Bouazza, A., and Singh, R. M. (2016). "Heat transfer enhancement of geothermal energy piles." Renewable and Sustainable Energy Reviews, 57, 16-33. https://doi.org/10.1016/j.rser.2015.12.065

Feng, J.-C., Wang, Y., Li, X.-S., Li, G., and Chen, Z.-Y. (2015). "Production behaviors and heat transfer characteristics of methane hydrate dissociation by depressurization in conjunction with warm water stimulation with dual horizontal wells." Energy, 79, 315-324. https://doi.org/10.1016/j.energy.2014.11.018.

Gao, Z., Bian, L., Hu, Y., Wang, L., and Fan, J. (2007). "Determination of soil temperature in an arid region." Journal of Arid Environments, 71(2), 157-168. https://doi.org/10.1016/j.jaridenv.2007.03.012

Gao, Z., Horton, R., Wang, L., Liu, H., and Wen, J. (2008). "An improved force-restore method for soil temperature prediction." European Journal of Soil Science, 59(5), 972-981. https://doi.org/10.1111/j.1365-2389.2008.01060.x.

Han, H., \& Huang, Z. (2002). A class of artificial boundary conditions for heat equation in unbounded domains. Computers \& Mathematics with applications, 43(6-7), 889-900. https://doi.org/10.1016/S0898-1221(01)00329-7

Heusinkveld, B. ., Jacobs, A. F. ., Holtslag, A. A. ., and Berkowicz, S. . (2004). "Surface energy balance closure in an arid region: role of soil heat flux." Agricultural and Forest Meteorology, 122(1), 21-37. https://doi.org/10.1016/j.agrformet.2003.09.005.

Kadali, S., Lakeshmi, S. S., Sharma, S., and Singh, D. N. (2013). "Investigations to establish the influence of the thermal energy field on soil properties." ACTA Geotechnica Solvenica, 10(2), $59-76$. http://fgserver6.fg.um.si/journal-ags/pdfs/AGS 2013-2 article 5.pdf

Knellwolf, C., Peron, H., and Laloui, L. (2011). "Geotechnical Analysis of Heat Exchanger Piles." Journal of Geotechnical and Geoenvironmental Engineering, American Society of Civil Engineers, 137(10), 890-902. https://doi.org/10.1061/(ASCE)GT.1943-5606.0000513.

Krishnaiah, S., and Singh, D. N. (2004). "Centrifuge modelling of heat migration in soils." 
International Journal of Physical Modelling in Geotechnics, 4(3), 39-47.

https://doi.org/10.1680/ijpmg.2004.040303.

Lazzaroni, E. F., Elsholkami, M., Arbiv, I., Martelli, E., Elkamel, A., and Fowler, M. (2016). "Energy infrastructure modeling for the oil sands industry: Current situation." Applied Energy, 181, 435445. https://doi.org/10.1016/j.apenergy.2016.08.072

Lee, J., Kim, J.-T., Chung, I.-M., and Kim, N. W. (2010). "Analytical solution for heat and moisture diffusion in layered materials." Canadian Geotechnical Journal, 47(6), 595-608. https://doi.org/10.1139/T09-125

LeVeque, R. J. (2002). Finite volume methods for hyperbolic problems. Cambridge University Press, Cambridge, United Kingdom

Liebethal, C., and Foken, T. (2007). "Evaluation of six parameterization approaches for the ground heat flux." Theoretical and Applied Climatology, Springer-Verlag, 88(1-2), 43-56. https://doi.org10.1007/s00704-005-0234-0

Loveridge, F., and Powrie, W. (2013). "Temperature response functions (G-functions) for single pile heat exchangers." Energy, 57, 554-564. https://doi.org/10.1016/j.energy.2013.04.060

Mandal, A., Chakravarthy, C. P., Nanda, A., Rath, R., and Usmani, A. (2013). "Analysis and design approach for large storage caverns." International Journal of Geomechanics, American Society of Civil Engineers, 13(1), 69-75. https://doi.org/10.1061/(ASCE)GM.1943-5622.0000180

Manthena, K., and Singh, D. (2001). "Measuring soil thermal resistivity in a geotechnical centrifuge." International Journal of Physical Modelling in Geotechnics, 1(4), 29-34. https://doi.org/10.1680/ijpmg.2001.010403

McCartney, J. S., Sánchez, M., and Tomac, I. (2016). "Energy geotechnics: Advances in subsurface energy recovery, storage, exchange, and waste management." Computers and Geotechnics, $\mathbf{7 5}$, 244-256. https://doi.org/10.1016/j.compgeo.2016.01.002

Mondal, S., Padmakumar, G. P., Sharma, V., Singh, D. N., and Baghini, M. S. (2016). “A methodology to determine thermal conductivity of soils from flux measurement." Geomechanics and Geoengineering, 11(1), 73-85. https://doi.org/10.1080/17486025.2015.1020346

Mondal, S., Sharma, V., Singh, D. N., and Baghini, M. S. (2017). "Determination of Thermal Regime in Sandy Soils: Mathematical Framework ATHERES." International Journal of Geomechanics, 17(9), 4017045. https://doi.org/10.1061/(ASCE)GM.1943-5622.0000918

Mondal, S., Singh, D. N., \& Baghini, M. S. (2018). Detection of thermal response of geomaterials: a critical appraisal. Emerging Materials Research, 7(3), 178-191. https://doi.org/10.1680/jemmr.16.00156

Ochsner, T. E., Sauer, T. J., and Horton, R. (2007). "Soil heat storage measurements in energy balance studies." Agronomy Journal, American Society of Agronomy, 99(1), 311-319. https://doi.org/10.2134/agronj2005.0103S

Padmakumar, G. P. (2013). "Laboratory investigations on heat migration through soil mass." Indian Institute of Technology Bombay, India.

Rao, M. V. B. B. G., and Singh, D. N. (1999). "A generalized relationship to estimate thermal resistivity of soils." Canadian Geotechnical Journal, NRC Research Press Ottawa, Canada, 36(4), 767-773. https://doi.org/10.1139/t99-037

Salciarini, D., Ronchi, F., Cattoni, E., and Tamagnini, C. (2013). "Thermomechanical effects induced by energy piles operation in a small piled raft." International Journal of Geomechanics, American Society of Civil Engineers, 15(2), 4014042. https://doi.org/10.1061/(ASCE)GM.1943-5622.0000375

Sharratt, B. S., Campbell, G. S., and Glenn, D. M. (1992). "Soil heat flux estimation based on the finite-difference form of the transient heat flow equation." Agricultural and Forest Meteorology, Elsevier, 61(1), 95-111. 
https://doi.org/10.1016/0168-1923(92)90027-2

Song, Y., Cheng, C., Zhao, J., Zhu, Z., Liu, W., Yang, M., and Xue, K. (2015). "Evaluation of gas production from methane hydrates using depressurization, thermal stimulation and combined methods." Applied Energy, 145, 265-277. https://doi.org/10.1016/j.apenergy.2015.02.040

Song, Y., Wang, J., Liu, Y., and Zhao, J. (2016). "Analysis of heat transfer influences on gas production from methane hydrates using a combined method." International Journal of Heat and Mass Transfer, 92, 766-773. https://doi.org/10.1016/j.ijheatmasstransfer.2015.08.102

Timlin, D. J., Pachepsky, Y., Acock, B. A., Šimunek, J., Flerchinger, G., and Whisler, F. (2002). "Error analysis of soil temperature simulations using measured and estimated hourly weather data with 2DSOIL." Agricultural Systems, 72(3), 215-239. https://doi.org/10.1016/S0308-521X(01)00075-0

Usmani, A., Kannan, G., Nanda, A., and Jain, S. K. (2015). "Seepage behavior and grouting effects for large rock caverns." International Journal of Geomechanics, American Society of Civil Engineers, 15(3), 6014023. https://doi.org/10.1061/(ASCE)GM.1943-5622.0000449

Velmurugan, V., and Srithar, K. (2008). "Prospects and scopes of solar pond: A detailed review." Renewable and Sustainable Energy Reviews, 12(8), 2253-2263. https://doi.org/10.1016/j.rser.2007.03.011

Wang, L., Gao, Z., Horton, R., Lenschow, D. H., Meng, K., and Jaynes, D. B. (2012). "An analytical solution to the one-dimensional heat conduction-convection equation in soil." Soil Science Society of America Journal, The Soil Science Society of America, Inc., 76(6), 1978-1986. https://doi.org/10.2136/sssaj2012.0023N

Wang, Z.-H., Bou-Zeid, E., and Smith, J. A. (2011). "A Spatially-Analytical Scheme for Surface Temperatures and Conductive Heat Fluxes in Urban Canopy Models." Boundary-Layer Meteorology, Springer Netherlands, 138(2), 171-193. https://doi.org /10.1007\%2Fs10546-010-9552-6

$\mathrm{Wu}, \mathrm{X} .$, \& Sun, Z. Z. (2004). Convergence of difference scheme for heat equation in unbounded domains using artificial boundary conditions. Applied Numerical Mathematics, 50(2), 261-277. https://doi.org/10.1016/j.apnum.2004.01.001

Yavari, N., Tang, A. M., Pereira, J.-M., and Hassen, G. (2014). “A simple method for numerical modelling of mechanical behaviour of an energy pile." Géotechnique Letters, 4(2), 119-124. https://doi.org/10.1680/geolett.13.00053

\section{List of Tables}

Table 1. Thermal Properties of Sand used in this study

\section{List of Figures}

Figure 1. (a) The schematic diagram of experiment setup (b) The arrangement of heat flux sensors and thermocouples

Figure 2. Several trial models of FDM to fix the suitable additional depth in order to define end boundary

Figure 3. Thermal regime obtained at (a) $5 \mathrm{~cm}$ and (b) $9 \mathrm{~cm}$ depth for different additional depths in FDM and analytical model, for applied temp $60^{\circ} \mathrm{C}$, soil SI

Figure 4. Thermal regime obtained at (a) $5 \mathrm{~cm}$ and (b) $9 \mathrm{~cm}$ depth in FDM and experiment, for an applied temp $60^{\circ} \mathrm{C}$ in step, soil SI

Figure 5. Temperature profile obtained at 5 and $9 \mathrm{~cm}$ depth from experiment and COMSOL Multiphysics ${ }^{\circledR}$, for an applied temp $60^{\circ} \mathrm{C}$ in step, soil SI

Figure 6. Comparison of the temperature values at $5 \mathrm{~cm}$ depth obtained from the FDM and experiment

Figure 7. Comparison of the temperature values at $5 \mathrm{~cm}$ depth obtained from the COMSOL Multiphysics $^{\circledR}$, and experiment 
(a)

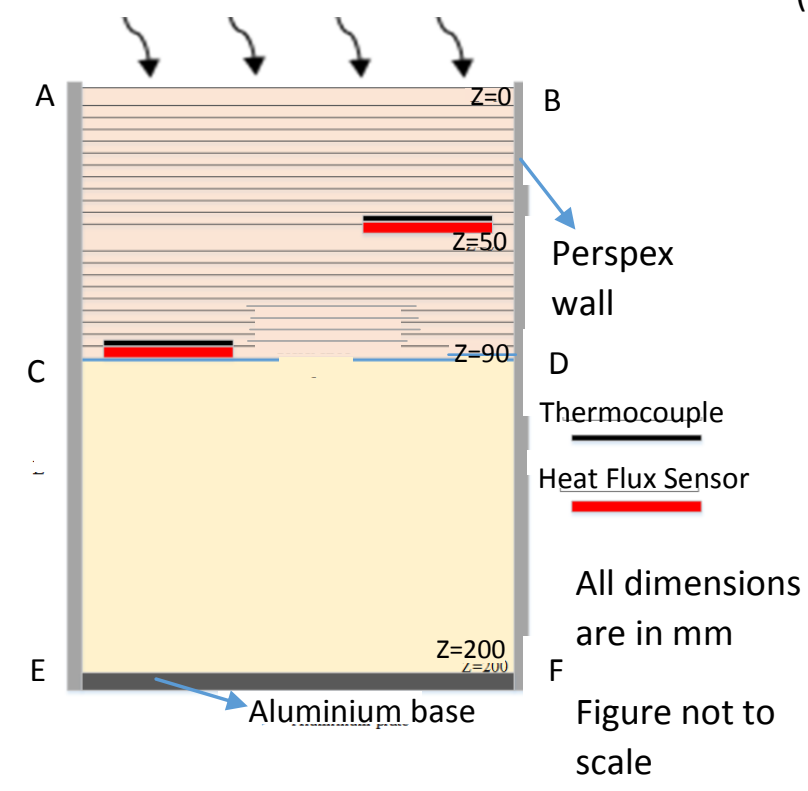

(b)

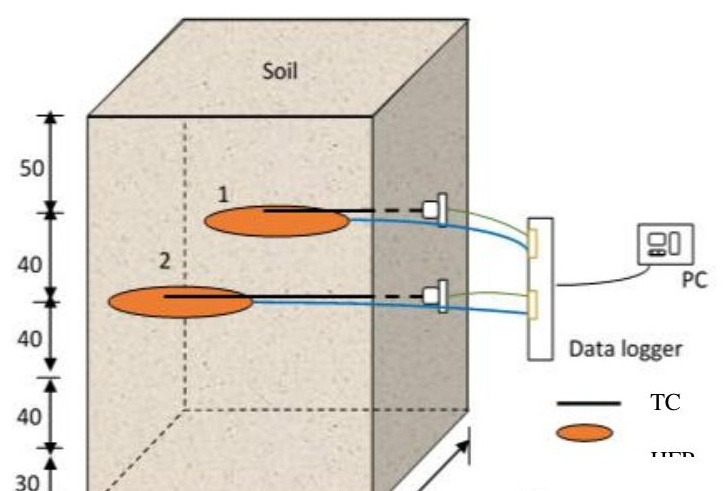

Figure not to

Figure 1. (a) The schematic diagram of experiment setup (b) The arrangement of heat thermocouples

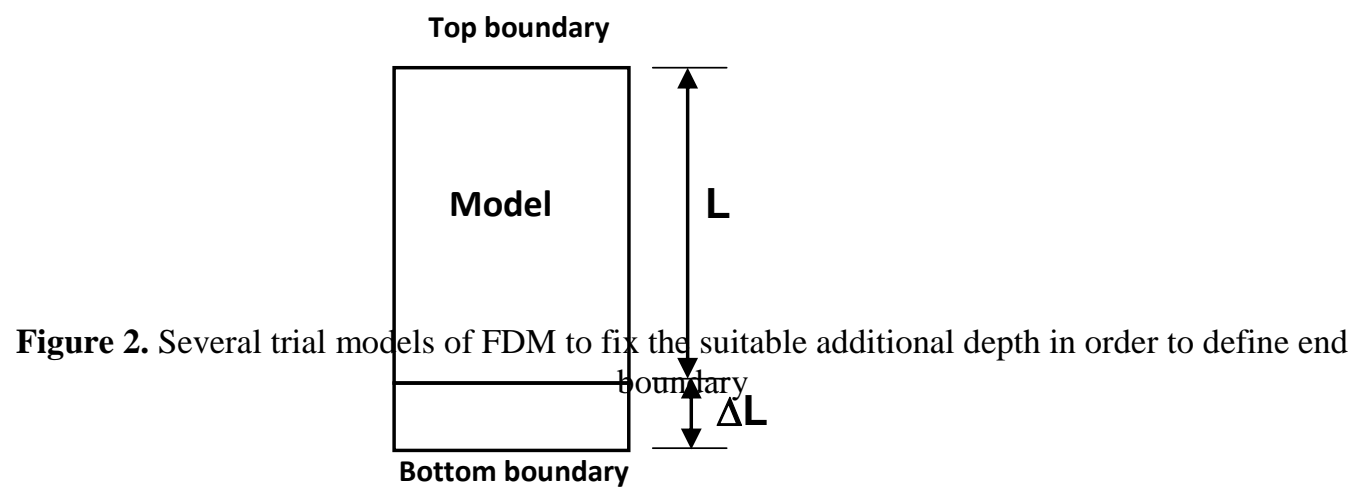



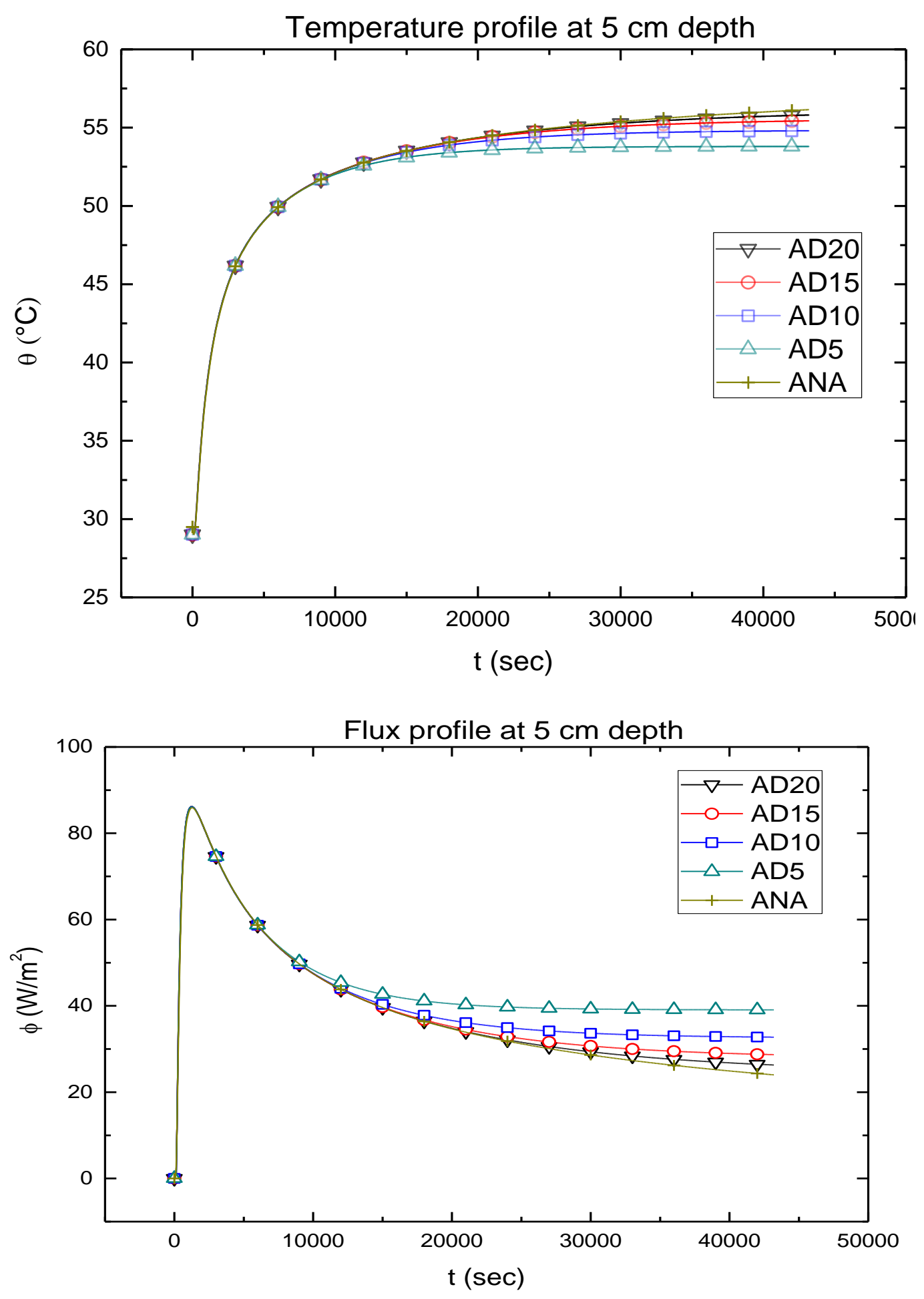

Figure 3(a). Thermal regime obtained at $5 \mathrm{~cm}$ depth for different additional depths in FDM and analytical model, for applied temp $60^{\circ} \mathrm{C}$, soil SI 


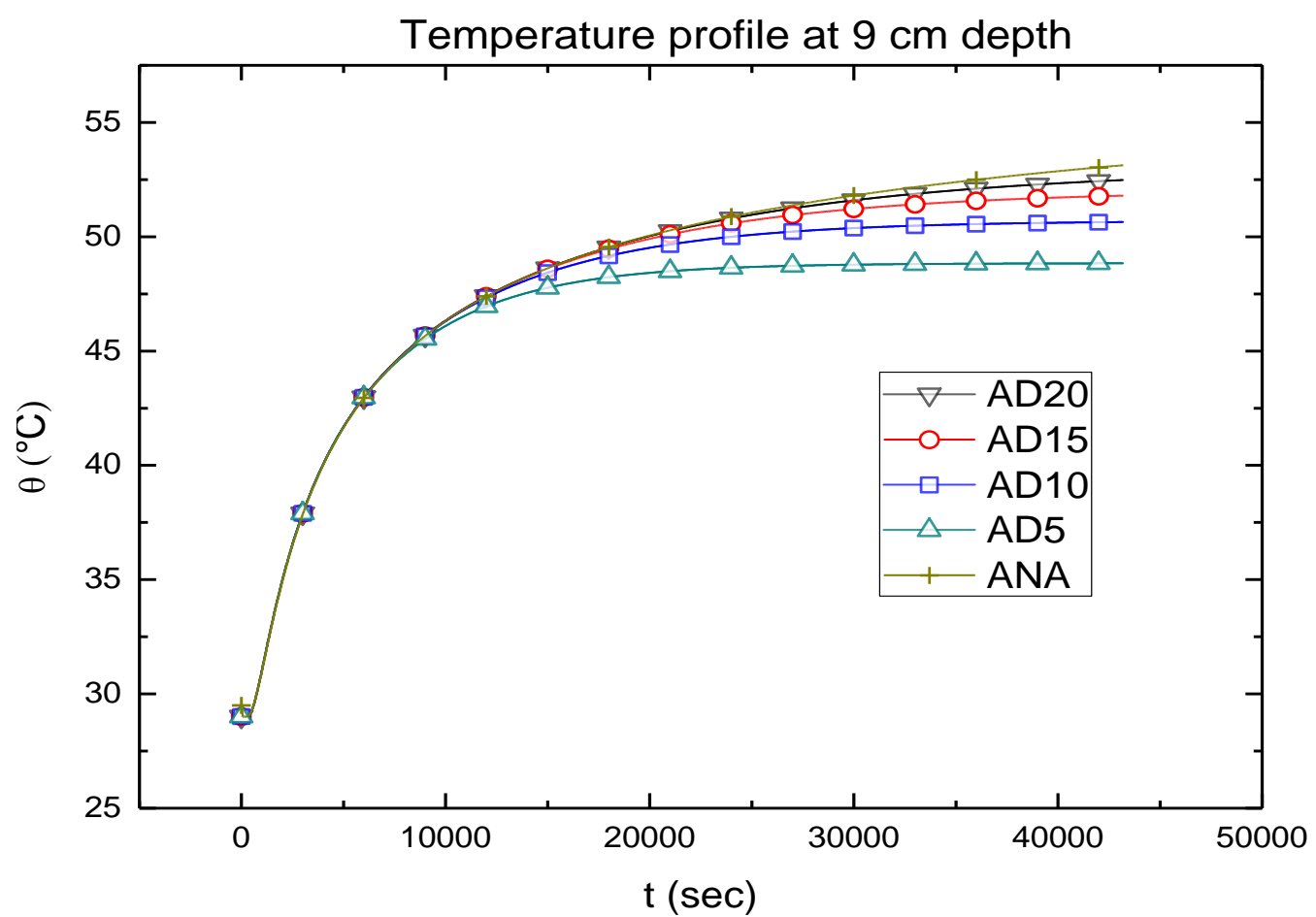

Flux profile at $9 \mathrm{~cm}$ depth

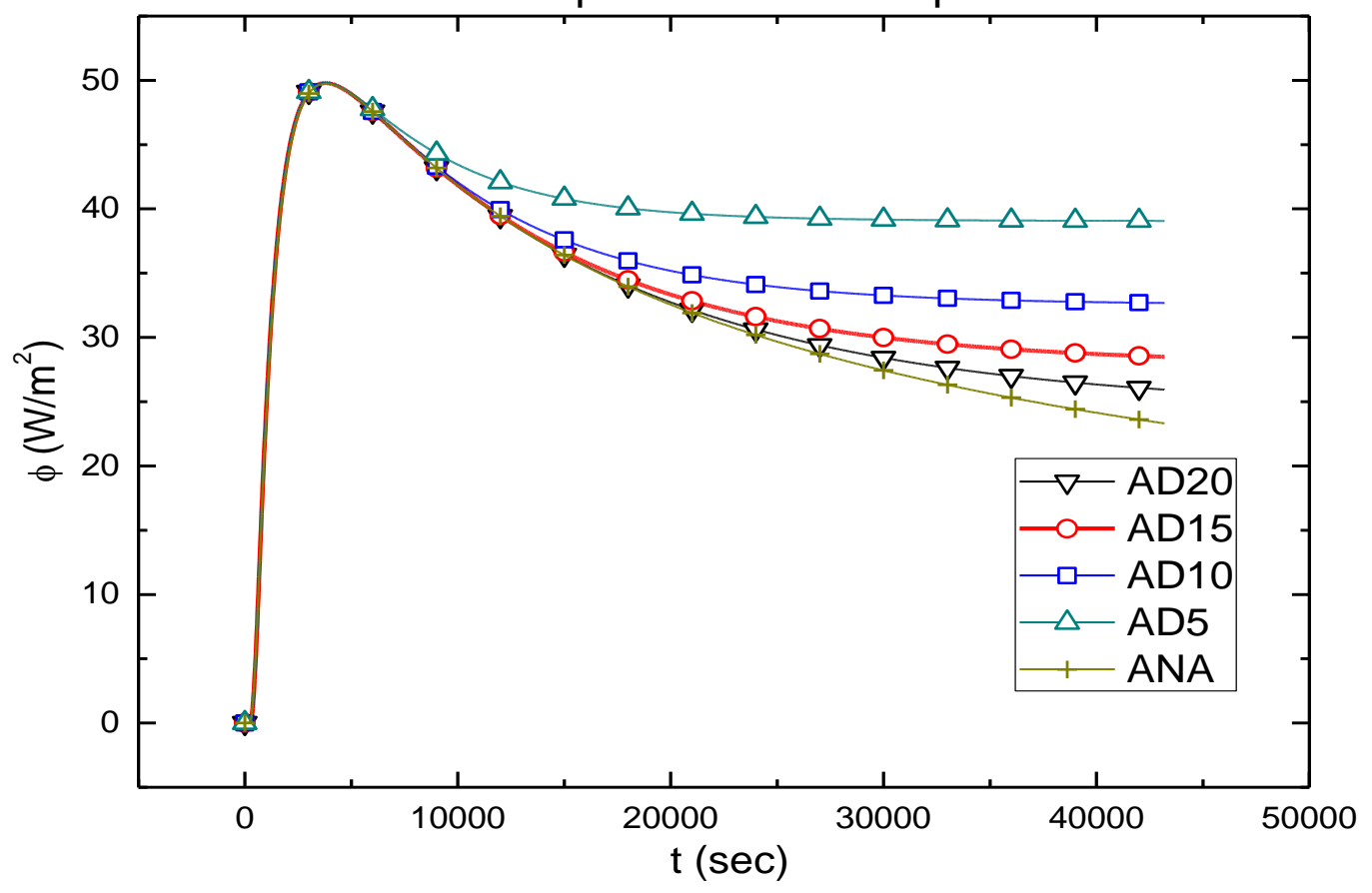

Figure 3(b). Thermal regime obtained at $9 \mathrm{~cm}$ depth for different additional depths in FDM and analytical model, for applied temp $60^{\circ} \mathrm{C}$, soil SI 


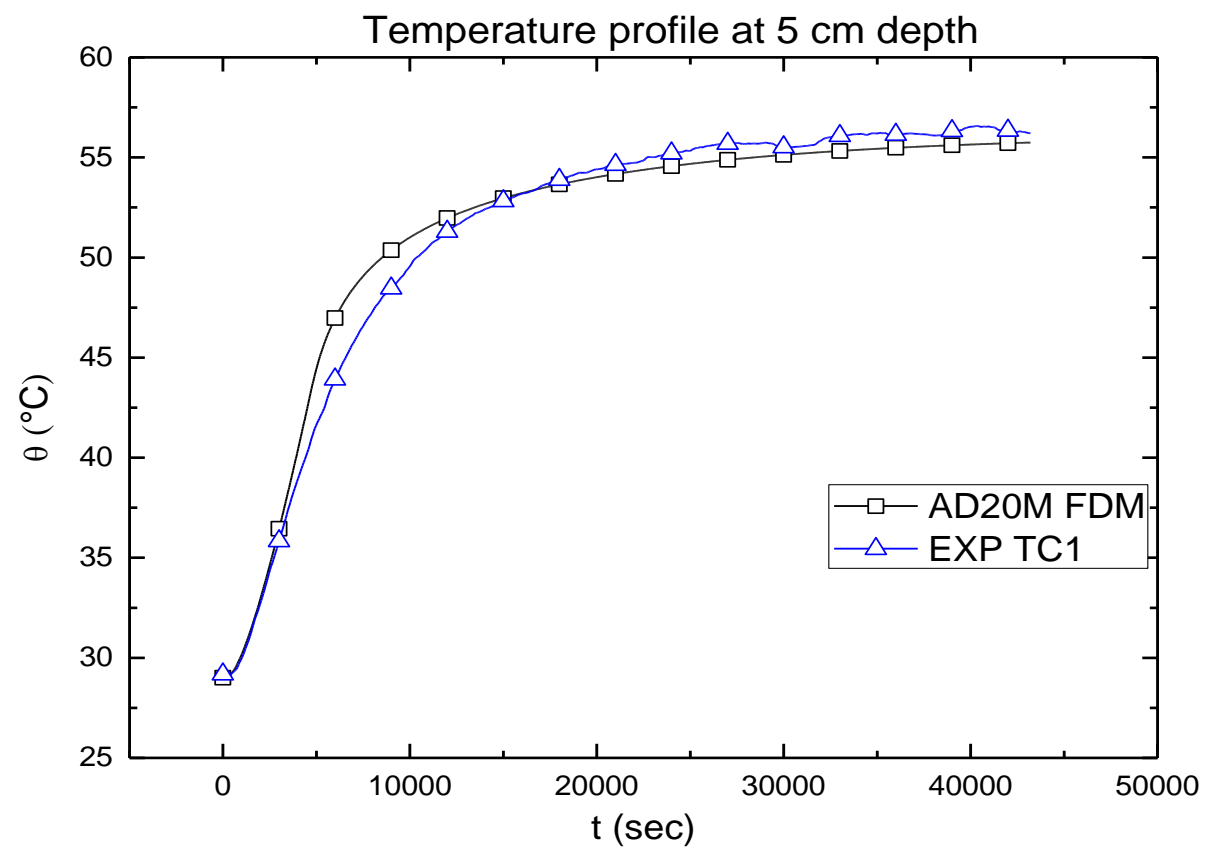

Flux profile at $5 \mathrm{~cm}$ depth

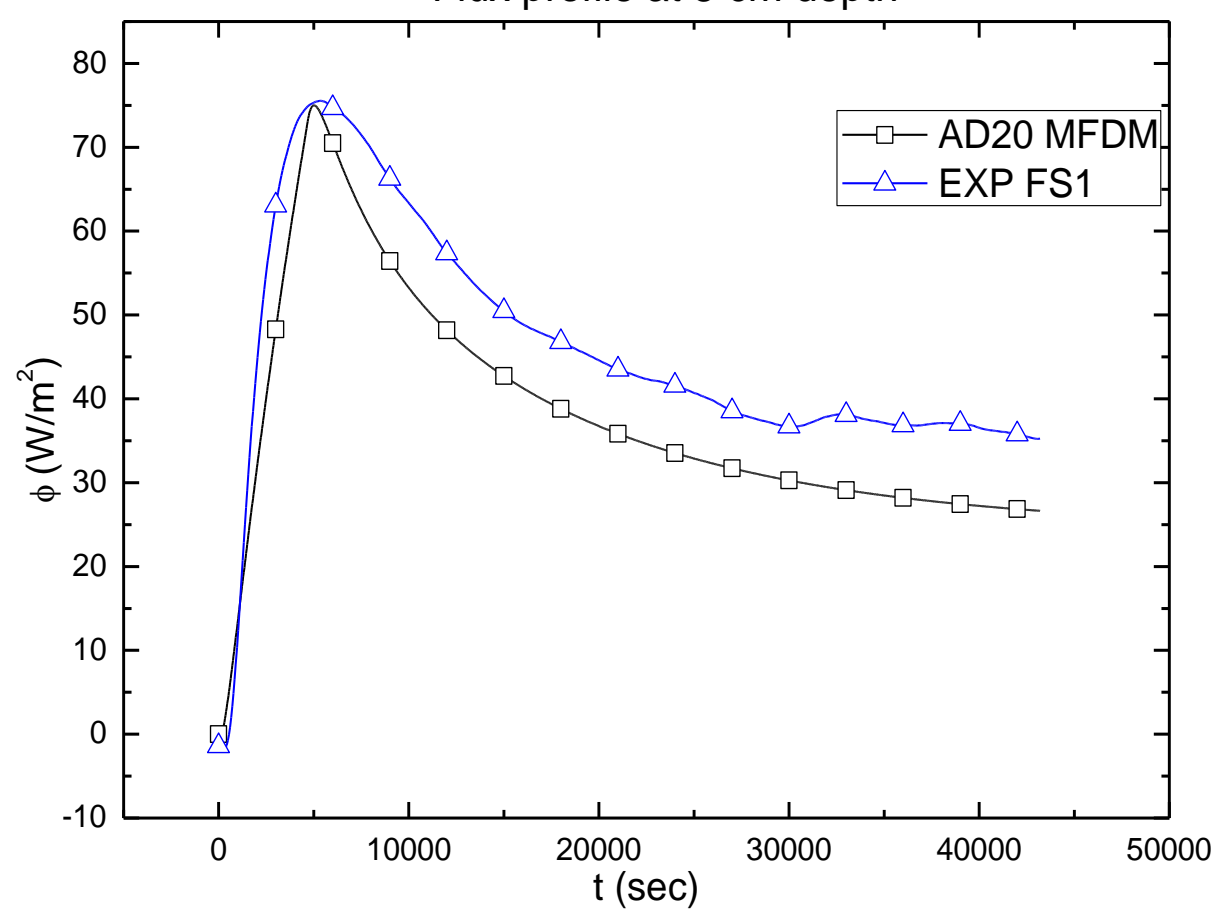

Figure 4(a). Thermal regime obtained at $5 \mathrm{~cm}$ depth in FDM and experiment, for an applied temp $60^{\circ} \mathrm{C}$ in step, soil SI 


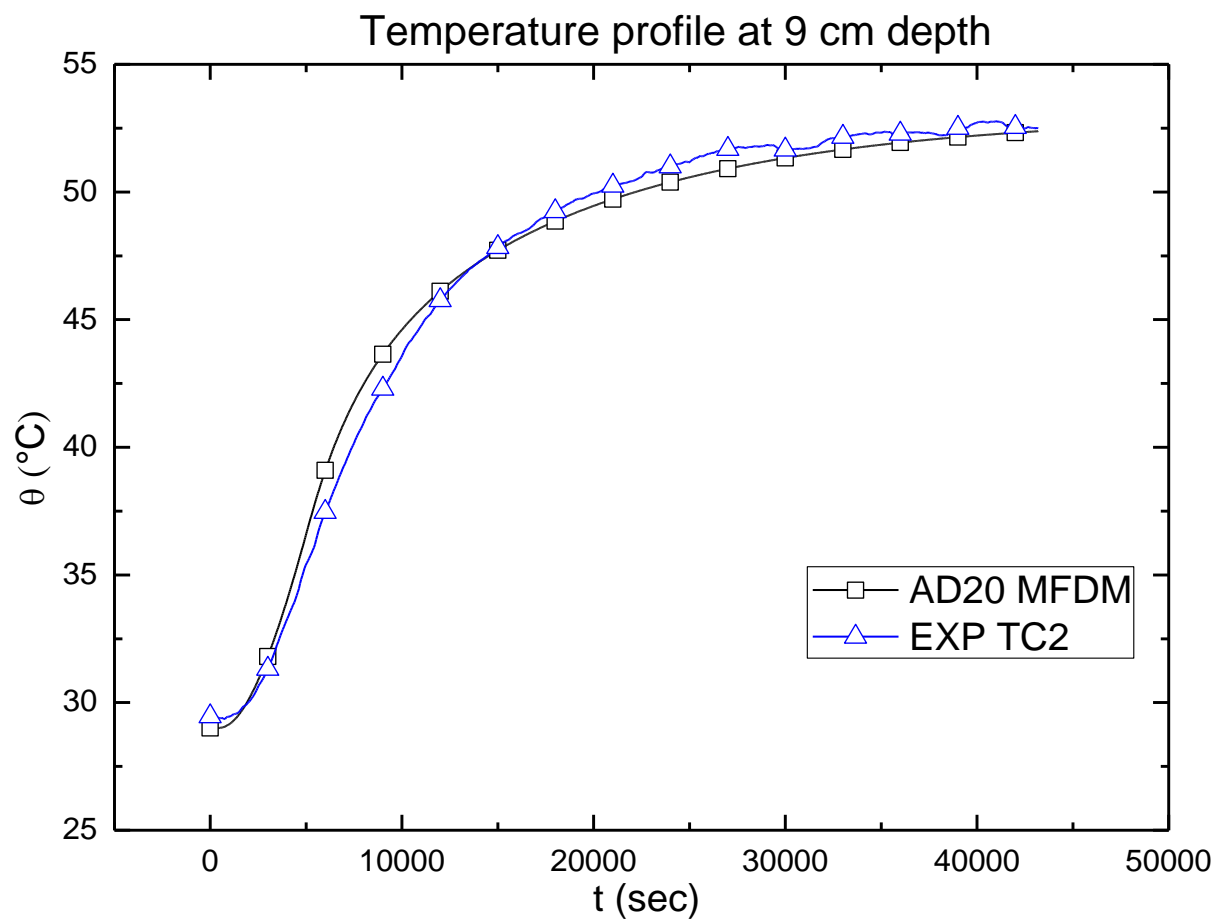

Flux profile at $9 \mathrm{~cm}$ depth

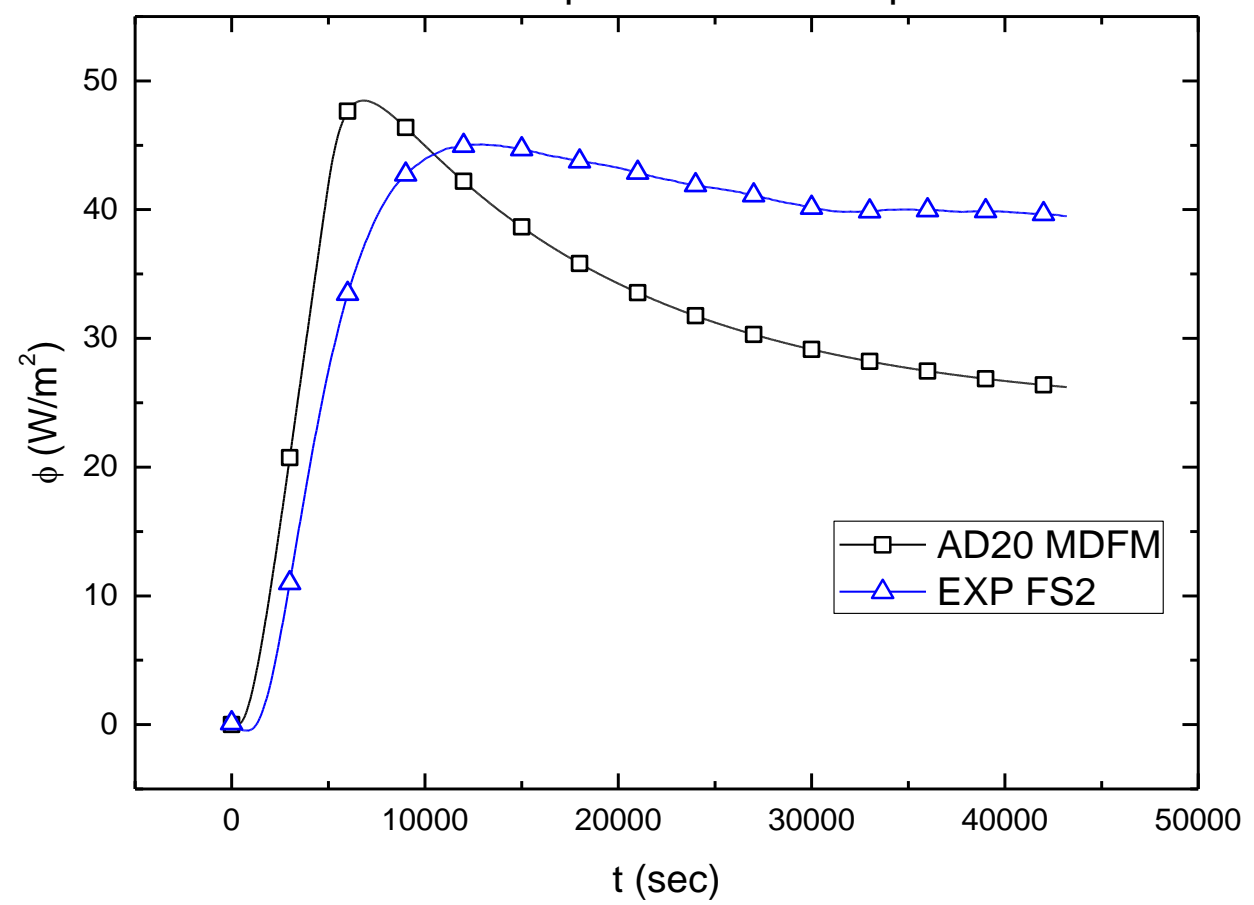

Figure 4(b). Thermal regime obtained at $9 \mathrm{~cm}$ depth in FDM and experiment, for an applied temp $60^{\circ} \mathrm{C}$ in step, soil SI 


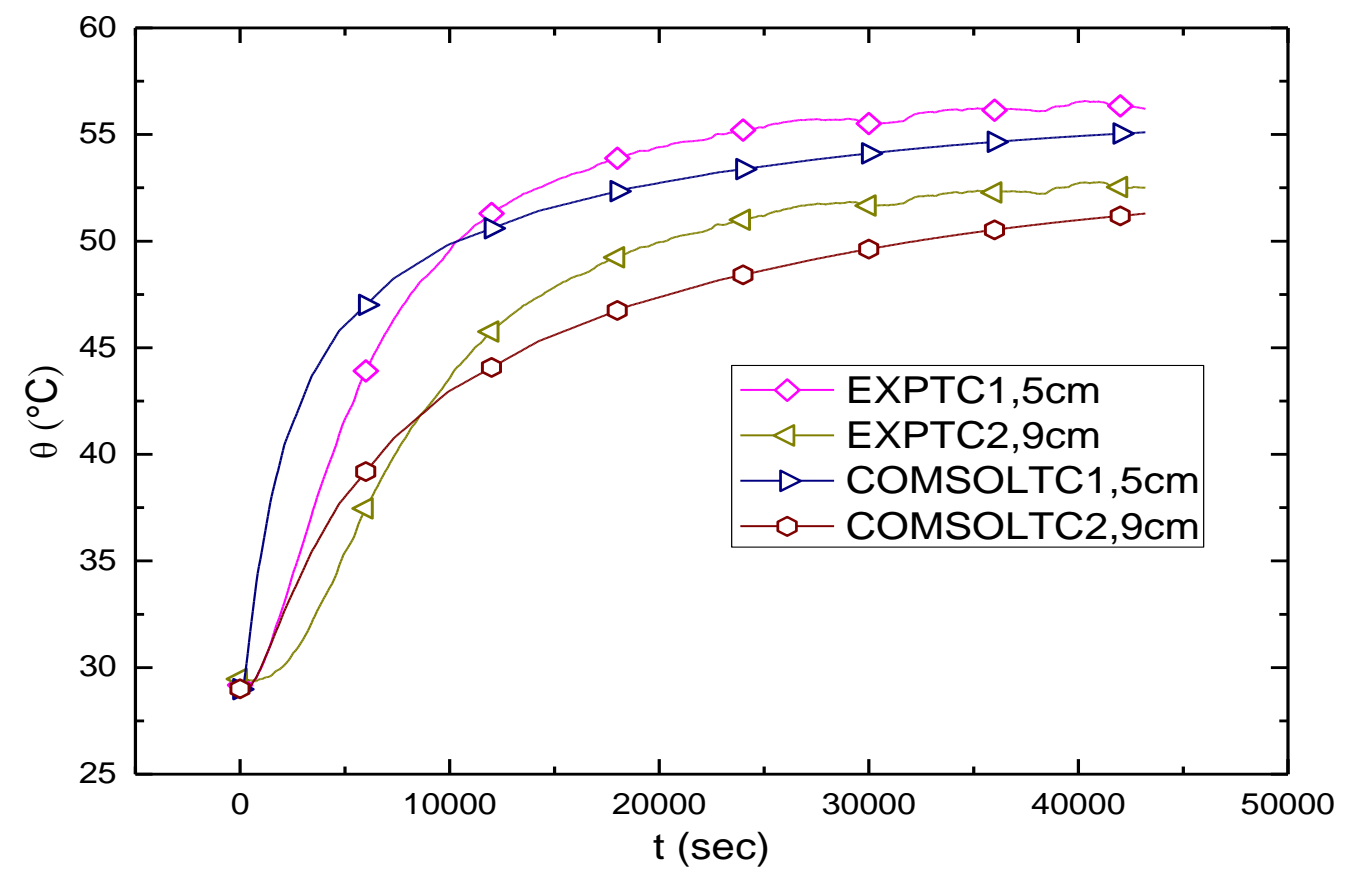

Figure 5. Temperature profile obtained at 5 and $9 \mathrm{~cm}$ depth from experiment and COMSOL Multiphysics ${ }^{\circledR}$, for an applied temp $60^{\circ} \mathrm{C}$ in step, soil SI 


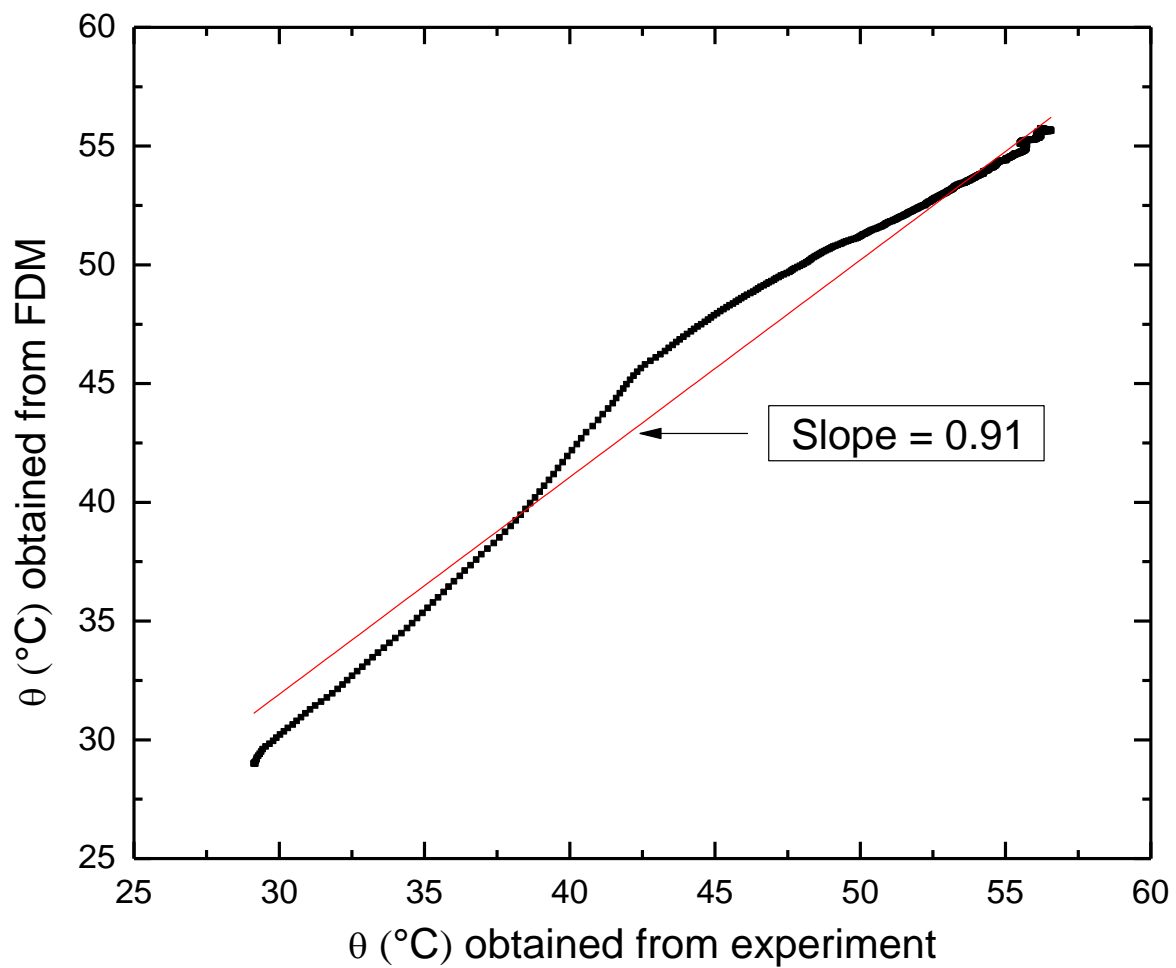

Figure 6. Comparison of the temperature values at $5 \mathrm{~cm}$ depth obtained from the FDM and experiment 


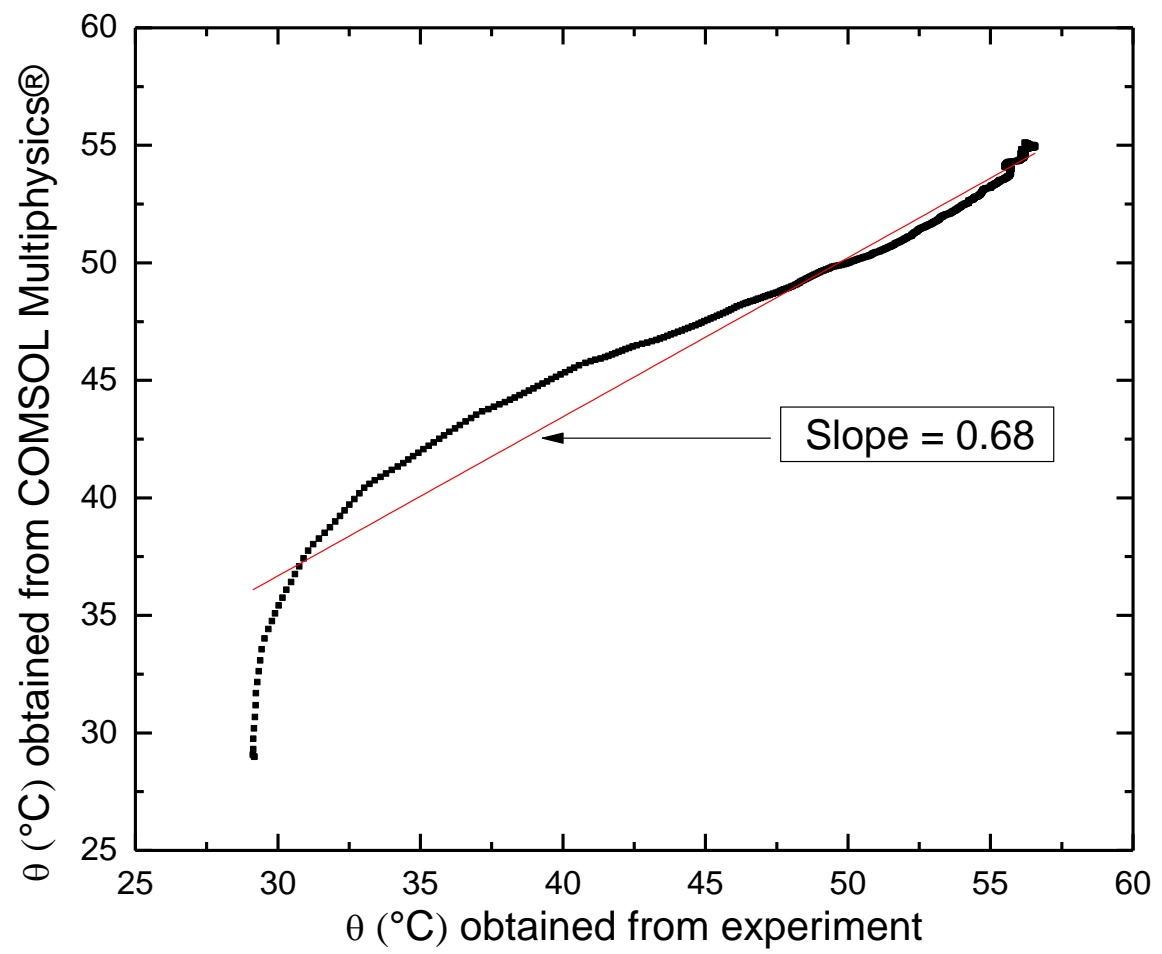

Figure 7. Comparison of the temperature values obtained at $5 \mathrm{~cm}$ depth from the COMSOL Multiphysics ${ }^{\circledR}$ and experiment 